sity and extension of rail track operational life as well as improvement of assembled rails and sleepers within curvilinear sections of small-diameter curvature, especially if connection joints are available. The obtained results may be applied in railway and commercial rail transport.

Keywords. Rail wear, curvilinear sections of rail track, loading, intermediate rail fastening.

Стаття надійшла до редакиії 13.11.2018

Рекомендовано до друку д-ром техн. наук, проф. Надутим В.П.

УДК [622.74:541.18]:625.032

ИСПОЛЬЗОВАНИЕ КОЛЕБАНИЙ ЖЕЛЕЗНОДОРОЖНЫХ ЦИСТЕРН ДЛЯ ПРИГОТОВЛЕНИЯ ВОДОУГОЛЬНОГО ТОПЛИВА ПРИ ЕГО ТРАНСПОРТИРОВКЕ

Семененко Е.В. ${ }^{1}$, Рубан В.Д. ${ }^{1}$, Подоляк К.К. ${ }^{1},{ }^{1}$ Рыжова С.А.

${ }^{1}$ Институт геотехнической механики им. Н.С. Полякова НАН Украины

ВИКОРИСТАННЯ КОЛИВАНЬ ЗАЛІЗНИЧНИХ ЦИСТЕРН ДЛЯ ПРИГОТУВАННЯ

ВОДОВУГІЛЬНОГО ПАЛИВА ПРИ ЙОГО ТРАНСПОРТУВАННІ

${ }^{1}$ Семененко Є.В., ' Рубан В.Д., ${ }^{1}$ Подоляк К.К., 'Рыжова С.О.

${ }^{1}$ Інститут геотехнічної механіки ім. М.С. Полякова НАН України

\title{
THE USE OF RAILWAY TANK OSCILLATIONS FOR PREPARING WATER-COAL FUEL
} DURING ITS TRANSPORTATION

${ }^{1}$ Semenenko E.V., ${ }^{1}$ Ruban V.D., ${ }^{1}$ Podolyak K.K., ${ }^{1}$ Rizhova S.A.

${ }^{1}$ Institute of Geotechnical Mechanics named by N. Poljakov NAS of Ukraine

Аннотация. Задекларированный в государственном документе переход на водоугольное топливо предполагает его транспортирование по трубопроводам, а также с использованием оборудования специальных высокотехнологических комплексов по приготовлению высококонцентрированной суспензии. Такой подход либо исключает использование существующих железнодорожных магистралей и требует строительства трубопроводов значительной протяженности, либо, при сохранении доставки углей на электростанции посредством железнодорожного транспорта, возникает необходимость в оборудовании комплексов измельчения угля, смешивания его с водой и гомогенизации суспензии. В обоих случаях необходимо отчуждение земли, а также существенные капитальные и временные затраты. Впервые предложено использовать для приготовления водоугольного топлива железнодорожные цистерны, в которых твердая фраза суспензии подвергается пропитыванию жидкой фазой и дезинтеграции под действием мелющих тел непосредственно во время транспортировки по железной дороге. В статье в рамках рассматриваемой технологии приготовления водоугольного топлива предложены формулы для оценки и обоснования технологических параметров процесса приготовления водоугольного топлива в железнодорожной цистерне с мелющими телами, которые предполагают пропитывание, дезинтеграцию и перемешивание компонентов водоугольного топлива во время доставки к потребителю железнодорожным транспортом. Установлены зависимости амплитуды и частоты вертикального перемещения материала в цистерне от скорости движения при их транспортировке по железнодорожным путям Днепровского региона, обоснованы длительность предварительного ожидания цистерны после заполнения до отправки, обеспечивающая пропитывание агломератов перед разрушением, а также объемы угля и воды, смешиваемые в цистерне.

Ключевые слова: водоугольное топливо, цистерна, железнодорожный транспорт, колебания вагона.

Введение. Согласно Энергетической стратегии Украины предполагается пе реход ТЭЦ на уголь, что позволит сэкономить до 6 млд. ${ }^{3}$ газа в год. В свете этого, тенденция перехода Украины на водоугольное топливо (ВУТ), исклю- 
ISSN 1607-4556 (Print), ISSN 2309-6004 (Online) Геотехнічна механіка. 2018. №142

чающее использование мазута и природного газа даже для подсветки котлов, работающих на угле, открывает привлекательные перспективы для разработки новых технологий его приготовления и транспортирования. Задекларированный в государственном документе переход на ВУТ предполагает его транспортирование по трубопроводам, а также с использованием оборудования специальных высокотехнологических комплексов по приготовлению высококонцентрированной суспензии [1-3]. Такой подход либо исключает использование существующих железнодорожных магистралей и требует строительства трубо проводов значительной протяженности, либо, при сохранении доставки углей на электростанции посредством железнодорожного транспорта, возникает необходимость в оборудовании комплексов измельчения угля, смешивания его с водой и гомогенизации суспензии.В обоих случаях необходимо отчуждение земли, а также существенные капитальные и временные затраты, что не обеспечивает максимально быстрого отказа от природного газа.

Альтернативой трубопроводному транспорту является технология получения и транспортирования ВУТ в железнодорожных цистернах, предложенная специалистами ИГТМ НАН Украины [4]. Известные технологии приготовления ВУТ предполагают три возможных варианта: смешивание после операции измельчения исходного угля, смешивание в процессе измельчения и смешивание воды с углем до подачи в мельницу. Как показывают результаты экспериментальных исследований, такое различие в технологии приготовления ВУТ позволяет изменить реологические характеристики суспензии, гранулометрические параметры измельченного угля и энергоемкость процесса измельчения [1]. В частности ВУТ, приготовленное с предварительным перемешиванием, обладает более высокими показателями по статической и динамической седиментационной стабильности, агрегативной устойчивости и реологическим характеристикам [1]. Таким образом, на основании результатов предварительных экспериментов, предлагается следующая технология [4,5]: исходный уголь вместе с мелющими телами засыпается в железнодорожные цистерны; заливается минимальным количеством водного раствора поверхностно-активного вещества; выдерживается некоторое время и отправляется из угольных регионов Украины в котельные, на ТЕЦ, тепловые электростанции и промышленные предприятия. Концентрация и свойства реагента подбираются таким образом, чтобы предотвратить замерзание суспензии за счет низкой температуры кристаллизации, обеспечить ее устойчивость, хорошее смачивание угля и его диспергирование под действием вибрации движущегося железнодорожного вагона до момента прибытия цистерн к потребителю. Из цистерн готовое ВУТ извлекается по трубопроводу и подается в технологический процесс.

Таким образом, для предлагаемой технологии необходимо обосновать возможные амплитуды и частоты вертикального перемещения материала в цистерне, длительность предварительного ожидания цистерны после заполнения до отправки, обеспечивающую пропитывание агломератов перед разрушением, а также объемы угля и воды, смешиваемые в цистерне.

С учетом известных оценок длительности процесса пропитывания пористых 
агломератов [6] и особенностей логистики железнодорожного транспорта, время предварительного ожидания цистерны после заполнения до отправки может быть рассчитано по формуле

$$
t_{*}=\frac{\eta b^{2} \delta_{s}^{2}}{6[K] \sigma \cos \theta_{s}}-\frac{L}{V}-t_{0},
$$

где $t_{*}$ - длительность предварительного ожидания цистерны после заполнения до отправки; $\eta$ - вязкость жидкости; $b$ - пористость угольных агломератов; $\delta_{s}$ крупность угольных агломератов; $[K]-$ проницаемость угольных агломератов; $\sigma-$ поверхностное натяжение жидкости; $\theta_{s}$ - угол смачивания; $L$ - дальность транспортирования; $V$ - средняя для данного перегона скорость движения поездов; $t_{0}-$ ожидаемое время простоев цистерны на сортировочных и стыковых станциях.

Плотность ВУТ, прежде всего, определяется ее объемной концентрацией, которая изменяется от 40 до $74 \%[1-3,5]$. В зависимости от концентрации и плотности фаз ВУТ изменяется и ее относительная плотность. Однако, учитывая, что объем и грузоподъемность железнодорожных цистерн уже регламентирована, то рассматриваемая цистерна может транспортировать ВУТ с плотностью не превышающей допустимую [5]

$$
\rho_{*}=0,82 \frac{G}{W}\left(\frac{D}{h}\right)^{1,42},
$$

где $\rho *$ допустимая относительная плотность груза; $\bar{h}$ - относительная высота заполнения цистерны; $G$ - грузоподъемность цистерны в тоннах; $W$ - объем кузова цистерны; $h$ - высота заполнения цистерны по вертикальному диаметру; $D$ - диаметр цистерны.

Нетрудно показать, что с учетом ограничений на концентрацию ВУТ, для рассматриваемой технологии могут быть использованы железнодорожные цистерны с допустимой относительной плотностью груза из следующего интервала значений $[5,7]$

$$
\frac{1+\rho_{S}}{2} \leq \rho_{*} \leq \frac{0,351+\rho_{S}}{1,351},
$$

где $\rho_{s}$ - относительная плотность угля, используемого для приготовления ВУТ.

При этом, нетрудно показать, что массовая концентрация ВУТ, а также массы смешиваемых в цистерне компонентов рассчитывают по следующим формулам [5, 7]

$$
C=\rho_{S} \frac{1-1,22 \frac{W}{G}\left(\frac{h}{D}\right)^{1,42}}{\rho_{S}-1}, \quad G_{S}=\frac{m C}{m+C} G, \quad G_{W}=\frac{m(1-C)}{m+C} G,
$$


ISSN 1607-4556 (Print), ISSN 2309-6004 (Online) Геотехнічна механіка. 2018. №142

где $C$ - массовая концентрация ВУТ; $G_{s}$ - масса угля, загружаемого в цистерну; $G_{W}$ - масса воды, заливаемой в цистерну; $m$ - количество тонн угля, приходящегося на одну тонну мелющих тел.

Вертикальные перемещения являются преобладающими колебаниями вагона на перегонах отечественных железных дорог Днепровского региона, для которых длина рельсов составляющих железнодорожное полотно равна 10 м, а скорость движения поезда изменяется в следующем интервале [8]

$$
2,6 \leq V \leq 3,6 .
$$

Для этих условий, пользуясь усредненными значениями коэффициента относительного трения рессор, коэффициента жесткости пути, жесткости рессор, вертикальное смещение вагона при движении поезда, вызванное преодолением стыков рельс и неравномерностью хода может быть описана следующей зависимостью [8]

$$
\begin{gathered}
z=5 \psi(\tau ; V)+4,25, \quad \tau=1,29 t, \\
\psi(\tau ; V)=\frac{2,153}{V^{2}-4,24} \cos (0,486 V \tau+2,45)-\cos \tau,
\end{gathered}
$$

где $z$ - вертикальное смещение вагона; $\psi$ - функция, характеризующая вертикальные периодические колебания вагона; $\tau$ - безразмерное время; $t$ - время.

Из первой формулы (6) нетрудно показать, что амплитуда колебаний груза, позволяющая мелющим телам производить размол угля, а также обеспечивающая самоизмельчение угля в цистерне, определяется согласно выражению:

$$
\Delta z=5 A, \quad A=\psi_{\text {max }}-\psi_{\text {min }},
$$

где $\psi_{\max }, \psi_{\min }$ - значение функции $\psi$ в двух следующих друг за другом экстремумах (табл. 1, рис. 1).

Таблица1 - Значение экстремумов функции $\psi$ в пределах одного периода для различных значений скорости движения вагона

\begin{tabular}{|c|c|c|c|c|c|c|}
\hline \multirow{2}{*}{$V, \mathrm{м} / \mathrm{c}$} & \multicolumn{2}{|c|}{ Экстремум №1 } & \multicolumn{2}{|c|}{ Экстремум №2 } & \multicolumn{2}{c|}{ Экстремум №3 } \\
\cline { 2 - 7 } & $\tau_{1}$ & $\psi_{1}$ & $\tau_{2}$ & $\psi_{2}$ & $\tau_{3}$ & $\psi_{3}$ \\
\hline 2,6 & 0,31 & $-1,77$ & 3,08 & 1,85 & 5,84 & $-1,69$ \\
\hline 2,8 & 0,27 & $-1,53$ & 2,98 & 1,57 & 5,68 & $-1,26$ \\
\hline 3 & 0,24 & $-1,40$ & 2,89 & 1,39 & 5,60 & $-0,94$ \\
\hline 3,2 & 0,20 & $-1,31$ & 2,83 & 1,25 & 5,75 & $-0,72$ \\
\hline 3,4 & 0,20 & $-1,25$ & 2,81 & 1,15 & & \\
\hline 3,6 & 0,17 & $-1,21$ & 2,76 & 1,06 & & \\
\hline
\end{tabular}

Из табл. 1 и рис. 1 видно, что функции $\psi$ в пределах одного периода, для скоростей из диапазона (5), имеет один доминирующий скачек, определяемый 
два минимума и один максимум. Таким образом, величина $A$ будет иметь один скачок (рис. 2) с длительностью близкой половине периода $\delta \tau=2,659$ (рис. 3).

При этом, зависимость величины $A$ от скорости вагона, с инженерной точностью $\left(R^{2}=0,9782\right)$, может быть аппроксимирована степенной функцией

$$
A=\frac{13,327}{V^{1,4}} .
$$

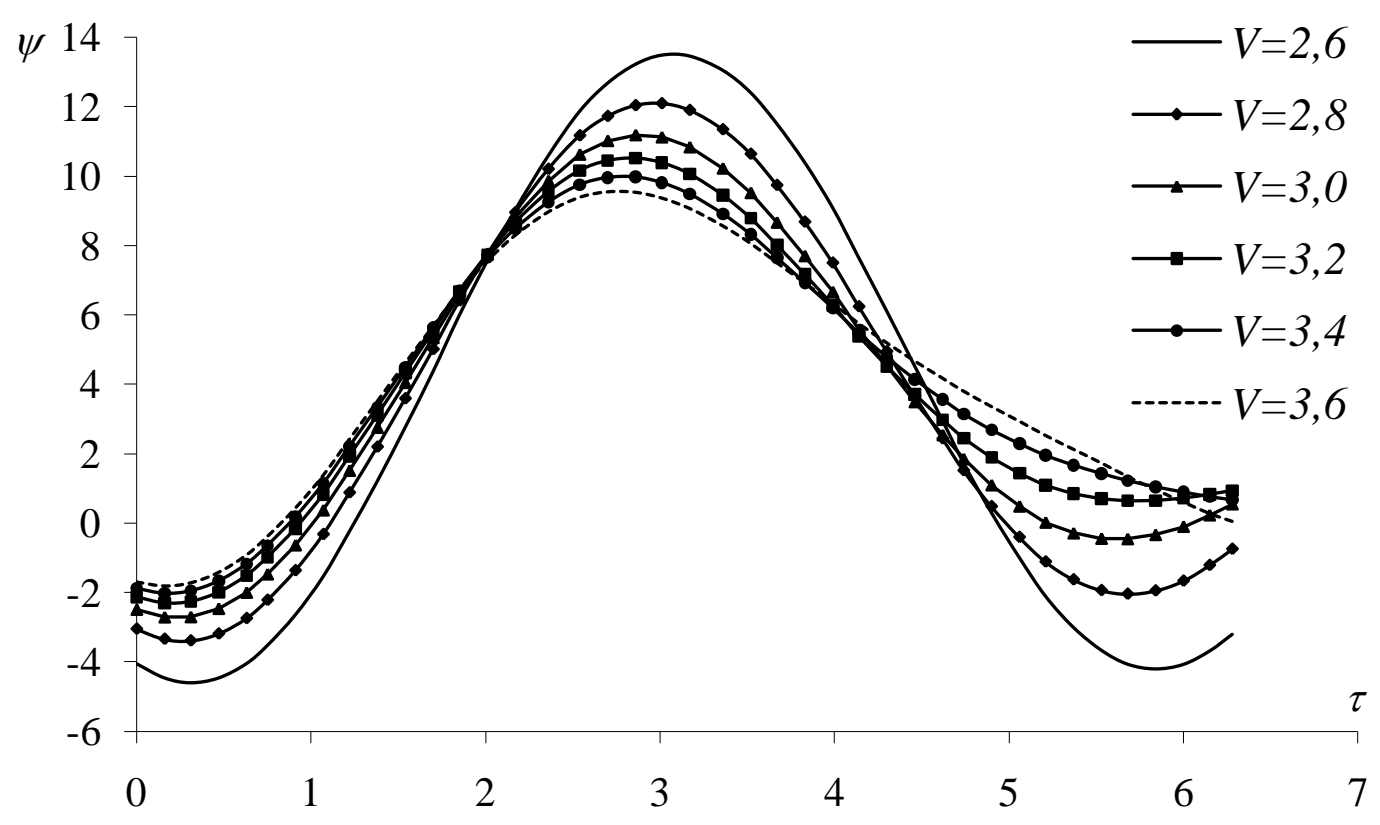

Рисунок 1 - Значение функции $\psi$ в пределах одного периода для различных значений скорости движения вагона

Таким образом, использование формул (1) - (9) дает возможность оценить возможные амплитуды и частоты вертикального перемещения материала в цистерне при их транспортировке по железнодорожным путям Днепровского региона, обосновать длительность предварительного ожидания цистерны после заполнения до отправки, обеспечивающую пропитывание агломератов перед разрушением, а также объемы угля и воды, смешиваемые в цистерне.

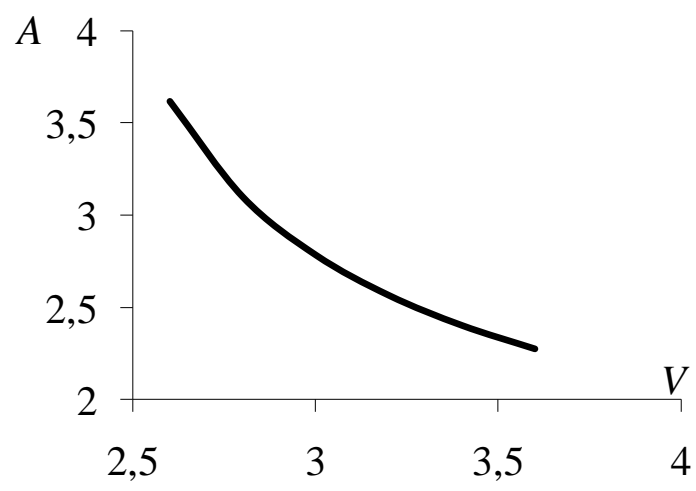

Рисунок 2 - Изменение величины $A$ от скорости вагона

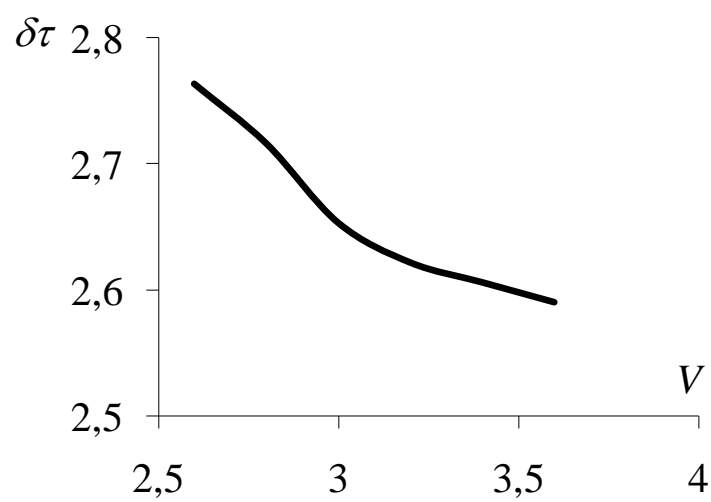

Рисунок 3 - Длительности скачка от скорости вагона 
Выводы. Впервые предложены формулы для оценки и обоснования технологических параметров процесса приготовления ВУТ в железнодорожной цистерне с мелющими телами, которые предполагают пропитывание, дезинтеграцию и перемешивание компонентов ВУТ во время доставки к потребителю железнодорожным транспортом.

\section{СПИСОК ЛИТЕРАТУРЫ}

1. Круть О.А. Водовугільне паливо. -К.: Наукова думка, 2002. 172 с.

2. Світлий Ю.Г., Круть О.А. Гідравлічний транспорт твердих матеріалів. - Донецьк.: Східний видавничий дім, 2010. 268 с.

3. Світлий Ю.Г., Білецький В.С. Гідравлічний транспорт. - Донецьк: Східний видавничий дім, 2009. 436 с.

4. Комлева И.Ю. Приготовление и использование водоугольного топлива в городе Днепропетровске / Сб. докладов II научно-практической консреренции молодых ученых «Проблемы и перспективы развития города Днепропетровска». Днепропетровск, 2012. С. 15.

5. Использование железнодорожной инфрраструктуры для доставки водоугольного топлива / Семененко Е.В., Рубан В.Д., Подоляк К.К. и др. / Збірник тез між нар. наук.-практ. конфф. «Логістичне управління та безпека руху на транспорті», м. Лозова, 4-8 травня 2015 р. С. 61-64.

6. Моделирование процесса пропитывания твердых частиц жидкостью при переработке углей / Семененко Е.В., Козарь И.Ю., Подоляк К.К. и др. / Геотехническая механика. Днепропетровск: ИГТМ НАНУ, 2013. Вып. 112. С. 108-117.

7. Семененко Е.В. Рубан В.Д., Подоляк К.К. Предельная концентрация водоугольных структурированных суспензий $/$ «Збагачення корисних копалин». Дніпропетровськ, 2015: Вып. 60 (101). С. 44-51.

8. Винокуров В.В. Исследование колебаний и устойчивости вагонов / Сборник научных трудов ДИИт. Вып.12. С. 292.

\section{REFERENCES}

1. Krut, O.A. (2002), Vodovugilne palivo [Water-coal fuel], Naukova Dumka, Kiev, Ukraine.

2. Svitliy, Yu.G. and Krut, O.A. (2010), Gidravlichniy transport tverdykh materialiv [Hydraulic transport of solid materials], Shidniy vydavnychiy dim, Donetsk, Ukraine.

3. Svitliy, Yu.G. and Biletskiy, V.S. (2009), Gidravlichniy transport [Hydraulic transport], Shidniy vydavnychiy dim, Donetsk, Ukraine.

4. Komleva, I.Yu. (2012), "Preparation and use of coal-fired petrol in the city of Dnepropetrovsk", Problemyi i perspektivyi razvitiya goroda Dnepropetrovska [Problems and Prospects of Development of Dnepropetrovsk city], Sbornik dokladov II nauchnoprakticheskoy konferentsii molodykh uchenykh [Collection of Reports of II Scientific-Practical Conference of Young Scientists] , P.15.

5. Semenenko, Ye.V., Ruban V.D., Podolyak, K.K., Ryzhova, S.A. (2015), "Use of railway infrastructure for delivery of water-coal fuel", Logistichne upravlinnya ta bezpeka ruhu na transporti [Logistic Management and Traffic Safety], Zbirnyk tez naukovopraktychnoy konferentsii [Collection of Reports of II Scientific-Practical Conference], Lozovaya, pp.61-64

6. Semenenko, Ye.V., Kozar, I.Yu., Podolyak K.K. and Ryzhova, S.A. (2013), "Design of process of saturating with of particulate matters aliquid at processing of coals", Geo-Technical Mechanics, no. 112, pp. 108-117.

7. Semenenko, Ye.V., Ruban V.D. and Podolyak, K.K. (2015), "Maximum concentration of the coal-water structured slurries", Zbagachennya korysnykh kopalyn, no. 60 (101), pp. 44-51.

8. Vinokurov, V.V. (2002), "Research of vibrations and stability of carriages", Sbornik nauchnykh trudov DIIT, no 12, p. 292.

\section{Об авторах}

Семененко Евгений Владимирович, доктор технических наук, старший научный сотрудник, заведующий отделом Проблем шахтных энергетических комплексов Института геотехнической механики им. Н.С. Полякова Национальной академии наук Украины (ИГТМ HАНУ), Днепр, Украина, EVSemenenko@nas.gov.ua.

Рубан Виталий Дмитриевич, магистр, младший научный сотрудник в отделе шахтных энергетических комплексов, Институт геотехнической механики им. Н.С. Полякова Национальной академии наук Украины (ИГТМ НАНУ), Днепр, Украина, igtm-ruban@i.ua

Подоляк Константин Константинович, магистр, инженер в отделе проблем шахтных энергетических комплексов, Институт геотехнической механики им. Н.С. Полякова Национальной академии наук Украины (ИГТМ НАНУ), Днепр, Украина, podolyak@email.ua

Рыжова Светлана Алексеевна, магистр, инженер отдела управления динамического проявления горного давления, Институт геотехнической механики им. Н.С. Полякова Национальной академии наук Украины (ИГТМ НАНУ), Днепр, Украина, evs_igtm@mail.ru

\section{About the authors}

Semenenko Eugeniy Vladimirovich, Doctor of Technical Sciences (D.Sc), Senior Researcher, Head of Department of Mine Energy Complexes, M.S. Polyakov Institute of Geotechnical Mechanics of the National Academy of Science of Ukraine (IGTM, NASU), Dnepr, Ukraine, EVSemenenko@nas.gov.ua.

Ruban Vitaliy Dmitrievich, Master of Science (M.S.), Junior Researcher in Department of Mine Energy Complexes, M.S. Polyakov Institute of Geotechnical Mechanics under the National Academy of Science of Ukraine (IGTM, NASU), Dnipro, 
Ukraine igtm-ruban@i.ua.

Podolyak Konstantin Konstantinovich, Master of Science (M.S.), Engineer at the Department of Mine Energy Complexes, M.S. Polyakov Institute of Geotechnical Mechanics under the National Academy of Science of Ukraine (IGTM, NASU), Dnipro, Ukraine, podolyak@email.ua.

Rizhova Svetlana Alekseevna, Master of Science (M.S.), Engineer at the Department of Pressure Dynamics Control in Rocks M.S. Polyakov Institute of Geotechnical Mechanics under the National Academy of Science of Ukraine (IGTM, NASU), Dnipro, Ukraine, evs_igtm@mail.ru.

Анотація. Задекларований в державному документі перехід на водовугільне паливо передбачає його транспортування по трубопроводах, а також з використанням обладнання спеціальних високотехнологічних комплексів з приготування висококонцентрованої суспензії. Такий підхід або виключає використання існуючих залізничних магістралей і вимагає будівництва трубопроводів значної протяжності, або, при збереженні доставки вугілля на електростанції за допомогою залізничного транспорту, виникає необхідність в обладнанні комплексів подрібнення вугілля, змішування його з водою і гомогенізації суспензії. В обох випадках необхідно відчуження землі, а також понести суттєві капітальні та часові витрати. Вперше запропоновано використовувати для приготування водовугільного палива залізничні цистерни, в яких тверда фраза суспензії піддається просочуванню рідкою фазою і дезінтеграції під дією тіл, що мелють, безпосередньо під час транспортування залізницею. У статті в рамках даної технології приготування водовугільного палива запропоновані формули для оцінки та обгрунтування технологічних параметрів процесу приготування водовугільного палива в залізничній цистерні з тілами, що мелють, які припускають просочування, дезінтеграцію і перемішування компонентів водовугільного палива під час доставки до споживача залізничним транспортом. Встановлено залежності амплітуди і частоти вертикального переміщення матеріалу в цистерні від швидкості руху при їх транспортуванні по залізничних коліях Дніпровського регіону, обгрунтовано тривалість попереднього очікування цистерни після заповнення до відправки, що забезпечує просочування агломератів перед руйнуванням, а також обсяги вугілля і води, що змішуються в цистерні.

Ключові слова: водовугільне паливо, цистерна, залізничний транспорт, коливання вагона

Annotation. The transition to water-coal fuel, declared in a government document, implies its transportation through pipelines, as well as using equipment of special high-tech complexes for preparing highly concentrated suspensions. This approach either eliminates the use of existing railways and requires the construction of pipelines of considerable length, or, while maintaining the delivery of coal to power plants through railway transport, there is a need to equip coal grinding complexes, mix it with water and homogenize the suspension. In both cases, alienation of land is necessary, as well as substantial capital and time costs. It is for the first time when it is proposed to use railway tanks for preparing water-based fuel, in which solid phase of the suspension is subject to soaking with the liquid phase and disintegrating under the action of grinding media directly during transportation by rail. In the article, within the framework of the considered technology for preparing water-based fuel, formulas are proposed for evaluating and justifying technological parameters for the process of preparing water-based fuel in a railway tank with grinding bodies, which imply the impregnation, disintegration and mixing of water-based fuel components during delivery to the consumer by rail. The dependences of the amplitude and frequency of vertical movement of material in the tank on the speed when they are transported along the railway tracks of the Dnieper region are established, preliminary waiting time of the tank after filling prior to shipment is justified, ensuring that the agglomerates are soaked before destruction, and the volumes of coal and water are mixed in the tank.

Keywords: water coal fuel, tank car, rail transport, wagon vibrations.

Стаття надійшла до редакції 28.11.2018

Рекомендовано до друку д-ром техн. наук, профр. Блюссом Б.О. 